\title{
Simulação em serviço de pisos de madeira jovem de Tectona grandis
}

\author{
Simulation in service of young \\ teak wood floors
}

\author{
Jeimy Blanco-Flórez, ${ }^{1}$, José Reinaldo Moreira da Silva ${ }^{2}$, \\ Pedro Paulo de Carvalho Braga ${ }^{1}$, José Tarcisio Lima", \\ Paulo Fernando Trugilho ${ }^{2}$
}

\footnotetext{
${ }^{1}$ Bolsista da CAPES/CNPq - Brasil-Doutorado, e-mail: jeicoblanco@hotmail.com, pedropaulobraga22@yahoo.com.br ${ }^{2}$ Programa de Pós-graduação em Ciência e Tecnologia da Madeira-Departamento de Ciências Florestais, Universidade Federal de Lavras, Lavras-MG e-mail: reinaldo@dcf.ufla.br, tarcisio@dcf.ufla.br, trugilho@dcf.ufla.br
}

\begin{abstract}
RESUMO
Pisos de madeira maciça possuem características de resistência mecânica que permitem sua utilização em determinado tipo de tráfego. A densidade e dureza do material são os principais indicadores de desempenho do tipo de madeira, mas devido a sua natureza, ela esta sujeita a riscos, danos por queda de objetos, arraste, desgaste por tráfego de pessoas, os quais afetam a sua estética, desempenho, entre outros. Espécies nativas provenientes da Amazônia são as principais usadas no Brasil para a fabricação de pisos de madeira, no entanto, existem espécies oriundas de reflorestamento com potencial de utilização para este tipo de uso. Ensaios de simulação em serviço se constituem em importante ferramenta de avaliação da qualidade de pisos de madeira como forma de antecipar à resposta em termos de desempenho em uso. Nesse sentido, este trabalho foi conduzido com o objetivo de avaliar o comportamento em serviço de pisos de madeira jovem de Tectona grandis a partir de ensaios de simulação em laboratório e recomendar o tipo de tráfego possível para a utilização desta madeira, visando subsidiar uma utilização potencial desse material na fase juvenil, que é amplamente plantado no Brasil. Realizaram-se ensaios de simulação em serviço (ASTM D2394-05) por meio de avaliação da resistência a esforços de carga rolante, endentação aplicada em pequenas áreas, impacto da esfera de aço, abrasão, determinação do coeficiente de atrito e rugosidade da superfície. Os resultados determinaram resistência baixa para endentação e impacto da esfera de aço, resistência moderada a esforços de carga rolante e resistência satisfatória para abrasão com potencial de utilização em tráfego leve a moderado para uso doméstico. O acabamento influenciou no coeficiente de atrito e na rugosidade da madeira
\end{abstract}

Palavras-chave: teca, ensaios mecânicos, rugosidade, resistência mecânica

\begin{abstract}
Hardwood floors has mechanical strength characteristics that allow its use in certain types of traffic. The basic density and hardness of the material are the main wood type of performance indicators, but due to its nature, it is subject to risks, damage by falling objects, drag, wear foot traffic, which affect its aesthetic and performance. Native species from the Amazon are the main used in Brazil for the manufacture of wood floors, however there are species from reforestation with potential use for this type of use. Simulated serving tests constitute an important quality assessment tool wood floors as a way to anticipate the response in terms of performance. In this sense this work was performed in order to evaluate the behavior in service of young hardwood floors Tectona grandis and thus support the potential use of this species widely planted in Brazil. There were simulated in-service testing (ASTM D2394-05) by evaluation of resistance to rolling load, indentation applied in small areas, falling-ball indentation, abrasion, friction coefficient, and determining surface roughness. The results showed low resistance to indentation applied in small areas and falling-ball indentation, moderate resistance to rolling load, favorable resistance to abrasion with potential for use in light to moderate traffic for domestic use. Finishing influenced the friction coefficient and surface roughness of wood.
\end{abstract}

Keywords: teak, mechanical tests, surface roughness, mechanical strength 


\section{INTRODUÇÃO}

O uso de madeira em pisos para melhorar a aparência de superfícies é considerado uma ação prática e atrativa.

A madeira como elemento construtivo proporciona estética agradável, benefícios de isolamento térmico e de resistência mecânica, facilidade de manutenção e longa duração com os cuidados adequados. Ao escolher o tipo de madeira para piso, um dos fatores principais a serem considerados é a densidade do material, pois madeiras mais densas são mais resistentes e mais utilizadas para este uso, tendo em vista que a densidade se relaciona diretamente com a dureza. Apesar do surgimento de materiais compósitos e engenheirados, a madeira maciça ainda é a mais demandada e utilizada para pisos, por exemplo, nos Estados Unidos há recente estudo acerca deste tema [1]. No Brasil, as principais espécies para fabricação de pisos são as nativas provenientes da Amazônia legal, entre as mais comercializadas estão o Jatobá, Tauari, Ipê, Cumaru, Maçaranduba, Pau marfim, entre outras [2]. O uso de madeira oriunda de reflorestamento para produção de pisos, ainda é escasso no Brasil [3]. Espécies potenciais como Eucalipto, Teca e a gramínea Bambu vêm sendo utilizadas em pequenas empresas, mas o emprego massivo destas matérias primas é limitado, devido em parte ao desconhecimento sobre as propriedades destas e outras espécies potencialmente aptas para este uso.

Uma espécie potencial para a utilização em pisos é a teca (Tectona grandis) a qual é mundialmente reconhecida como uma madeira de alta qualidade devido a suas excelentes propriedades, junto ao cedro (Cedrela odorata) e o Mogno (Swietenia macrophylla). É considerada umas das espécies mais valiosas devido a combinação de baixo peso específico com resistência, alta durabilidade natural e estabilidade dimensional e facilidade de usinagem, além da beleza estética [4]. A teca é utilizada para construção, fabricação de móveis, objetos de luxo e revestimentos de embarcações. Originaria do Sul da Ásia é a espécie de folhosa tropical mais plantada no mundo e cultivada há 150 anos em mais de 50 países dentro e fora da área de distribuição natural. [5]. No Brasil foi introduzida na região de Cáceres no Mato Grosso na década de 1970 e hoje cobre uma área plantada de 67,329 hectares em vários estados do país [3]. A madeira de teca é cortada em ciclos que variam de 15 a 30 anos, em lugar da longa rotação de 120-150 anos [6]. Árvores com diâmetros entre $(12-30 \mathrm{~cm})$ geram toras de menor qualidade e alta proporção de madeira juvenil, contudo estudos confirmam a similaridade entre as de propriedades físicas e mecânicas de madeira de teca juvenil e adulta desta espécie [7,8]. Para usos específicos como pisos, assoalhos e decks, a teca apresenta potencial, mas ainda são escassas as informações sobre seu comportamento em serviço.

Comparativamente com outros materiais, a madeira em uso para pisos esta sujeita a riscos, danos por quedas de objetos, desgaste por elementos abrasivos, desgaste por tráfego de pessoas, arraste de objetos, entre outros.

A aplicação de revestimentos proporciona algum grau de proteção, mas estes tipos de cargas dinâmicas afetam de maneira significativa e danificam a superfície comprometendo-a estética e mecanicamente. Ensaios de simulação de pisos em uso se constituem em uma importante ferramenta para avaliar o comportamento em serviço de pisos de madeira [9]. Esses procedimentos foram avaliados e aprovados pela AMERICAN SOCIETY FOR TESTING AND MATERIALS (ASTM) e descritos inicialmente na norma D 2394-68 [10]. Os ensaios consistem em medir a resistência às cargas concentradas, a endentação causada por cargas aplicadas em pequenas áreas, a aplicação de esforço rolante, o impacto de esfera de aço e métodos, que também são descritos para determinar a abrasão da superfície, o coeficiente de atrito e o teste de umedecimento da superfície. Esta norma tem servido de base para avaliar o desempenho de pisos de madeira de espécies conhecidas ou não, sobre as quais é possível encontrar resultados disponíveis na literatura $[11,12,13,14,15,16]$.

O desempenho de pisos de madeira é observado a partir da utilização ao longo do tempo, assim, antecipar as informações sobre o uso em serviço do produto, bem como estabelecer critérios para fins de especificação proporcionaria mais segurança para avaliação da vida útil de pisos de madeira. Sendo o Brasil o maior reflorestador de Tectona grandis na América do Sul, e considerando as boas propriedades desta espécie em relação aos aspectos físicos, mecânicos e estéticos, é vista como uma espécie em potencial para a elaboração de produtos de maior valor agregado. O presente trabalho foi realizado com o objetivo de avaliar o comportamento em serviço de pisos de madeira jovem de Tectona grandis a partir de ensaios de simulação em laboratório e recomendar o tipo de tráfego possível para a utilização desta madeira.

\section{MATERIAIS E MÉTODOS}

Árvores de Tectona grandis, com 13 anos de idade, foram abatidas e retiraram-se três toras de 2,70 metros. A tora intermediária foi dividida em três partes e estas desdobradas tangencialmente, obtendo-se tábuas de 
$20 \mathrm{~mm}$ de espessura (Figura1). A secagem foi feita ao ar livre, por um período de três meses e posteriormente retirados os corpos de prova para cada ensaio (Tabela 2). A seguir, os corpos de prova foram acondicionados em câmara climática $\left[\mathrm{T}=(20 \pm 2)^{\circ} \mathrm{C}\right.$ e UR $=(60 \pm 5) \%$ ] até atingirem a umidade de equilíbrio de $12 \%$. Após acondicionamento foram realizados os ensaios de simulação de pisos em uso em ambiente controlado.

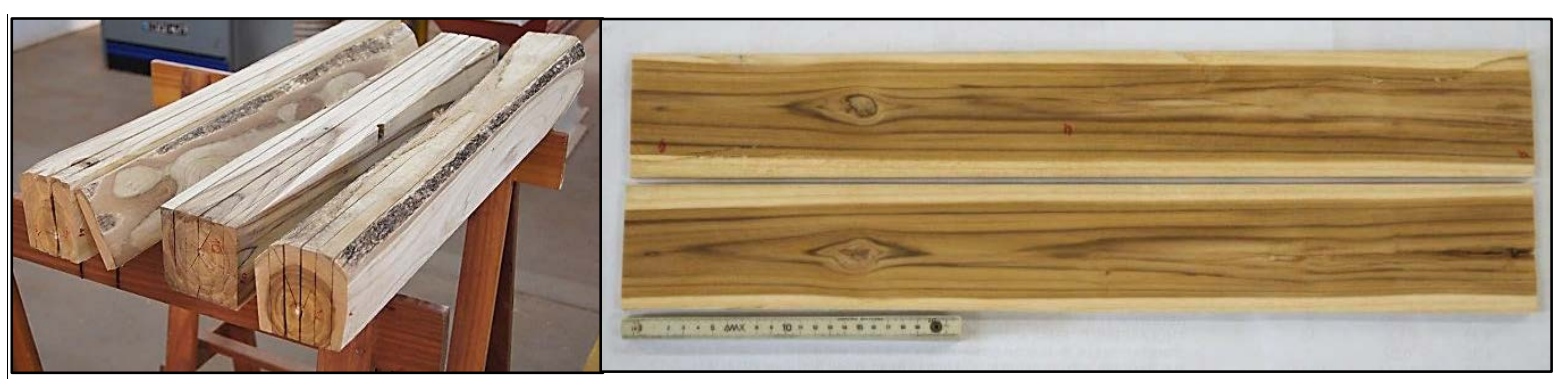

Figura 1: Obtenção de tábuas para confecção de pisos de madeira de teca

Tabela 2: Especificações dos ensaios de simulação de pisos na madeira de teca

\begin{tabular}{c|c|c}
\hline \multicolumn{1}{c|}{ ENSAIO } & \multicolumn{2}{c}{ CORPO DE PROVA } \\
\cline { 2 - 3 } & Dimensão (mm) & Número \\
\hline Resistência à carga rolante & 240 x 120 x 18 & 77 \\
\hline Endentação causada por cargas em pequenas áreas & 240 x 80 x 18 & 81 \\
\hline Resistência ao impacto da esfera de aço cadente & 240 x 120 x 18 & 42 \\
\hline Abrasão & $95 \times 95$ x 18 & 30 \\
\hline Atrito & $240 \times 150 \times 18$ & 43 \\
\hline
\end{tabular}

Fonte: ASTM D2394-05

\subsection{Ensaio de carga rolante}

Com este ensaio é possível obter a medida da resistência do piso de madeira quando submetido a cargas concentradas como deslocamento de móveis, caixas, pianos e outros objetos pesados. O aparelho de ensaio consiste de uma base de ferro de 1750 x $400 \mathrm{~mm}$, na qual são colocados os corpos de prova num ângulo de $45^{\circ}$ entre o eixo axial do corpo de prova e o sentido de deslocamento da carga. O equipamento é movimentado sobre dois trilhos e a roda central que exerce o esforço na madeira possui carga de $890 \mathrm{~N}$, movimentada com motor elétrico que desliza a unidade móvel em velocidade de 0,06 m/s. Após 10, 25 e 50 ciclos é medida a intensidade da depressão por meio de micrômetro (Figura 2 e 5).

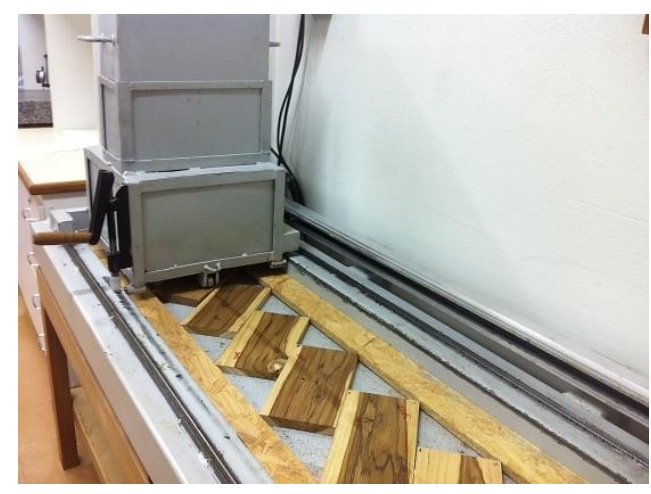

Figura 2: Equipamento para ensaio de carga rolante

\subsection{Ensaio de endentação em pequenas áreas}

Este ensaio permite obter a resistência de pisos de madeira a aplicação de cargas em pequenas áreas, como o caso de saltos de sapatos ou pequenos objetos que exercem cargas concentradas. É possível analisar a 
superfície da madeira após o ensaio, de forma qualitativa, a partir da observação e qualificação visual da superfície, e também quantitativamente por meio de medições da depressão causada pelo aparelho, por meio de micrômetro, esta última mais objetiva como padrão de comparação. O equipamento possui uma base de ferro, provido de um rolo com pinos de aproximadamente $5 \mathrm{~mm}$ de diâmetro, os quais exercem a carga distribuída de $890 \mathrm{~N}$, movimentado com motor elétrico à velocidade de $0,06 \mathrm{~m} / \mathrm{s}$. O ensaio consiste na avaliação da depressão (mm) causada na madeira por cada um dos pinos, após a passagem de 100 ciclos (uma passagem) do rolo sobre os corpos de prova, como mostrado na Figura 3 e 5.

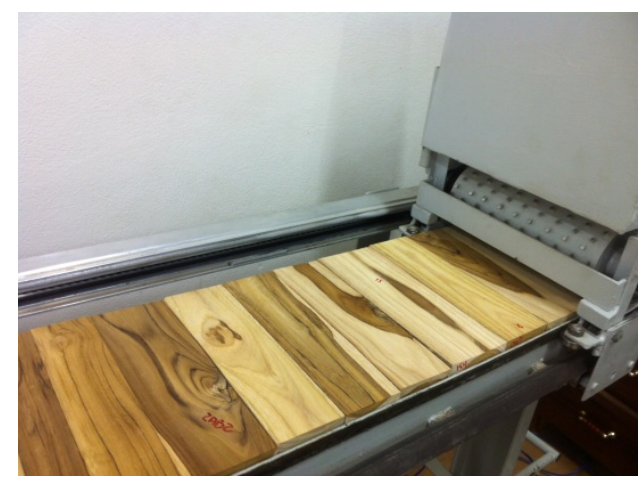

Figura 3: Equipamento para ensaio de endentação em pequenas áreas

\subsection{Ensaio da esfera de aço}

Este ensaio simula a eventual queda de objetos sobre o piso. O equipamento utilizado possui suportes a 12 diferentes alturas $(15 \mathrm{~cm}$ até $180 \mathrm{~cm}$ ) nas quais uma esfera de aço de $535 \mathrm{~g}$ e $51 \mathrm{~mm}$ de diâmetro é liberada de um dispositivo com eletroímã sobre a madeira. Para medir a endentação é utilizada uma folha de papel carbono sobre o corpo de prova, e realizada a medição com micrómetro da depressão originada pela queda da esfera na superfície da madeira (Figura 4).

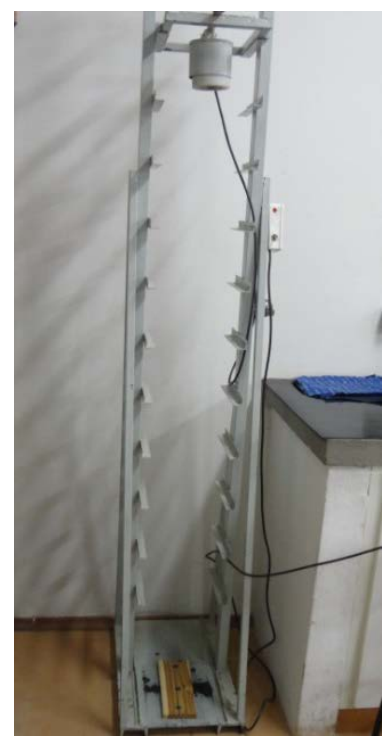

Figura 4: Aparelho para ensaio de impacto da esfera de aço 


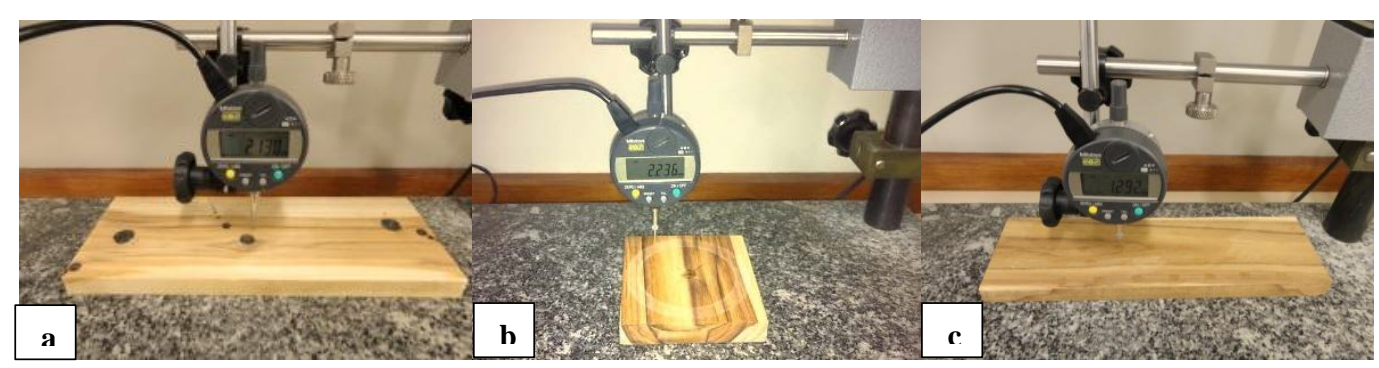

Figura 5: Medição da depressão na madeira após ensaios de simulação a)Impacto da esfera de aço, b)Ensaio de abrasão e c)Ensaio de endentação aplicada em pequenas áreas

\subsection{Ensaio de abrasão}

Este ensaio avalia a possibilidade de um piso de madeira ser utilizado para determinado tráfego de acordo com a sua resistência a forças abrasivas. O teste foi realizado no abrasímetro Taber abraser modelo 5135 que é provido de dois braços com cargas de $500 \mathrm{~g}$ em que são colocados discos abrasivos que giram sobre o corpo de prova a uma frequência de 72 ciclos/min, para um total de 500 ciclos. A madeira foi submetida ao desgaste sem produto de acabamento. No final foi mensurada a depressão originada pelo desgaste, que é obtida pela média das depressões interna e externa. Nas Figuras 5 e 6 observam-se o equipamento de ensaio de abrasão e a forma utilizada para a mensuração da depressão. A norma ABNT NBR 14833-1 classifica o tipo de tráfego de acordo com a resistência a abrasão da camada de revestimento para pisos de madeira laminados, porém para madeira maciça não existe norma, desta forma o padrão de comparação a empregar é a profundidade da depressão.

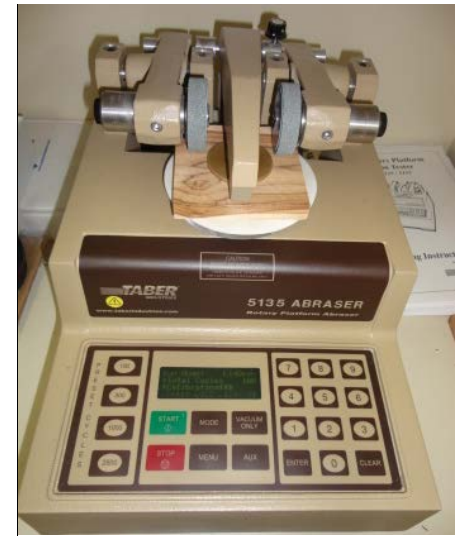

Figura 6: Abrasímetro TABER para ensaio de abrasão

\subsection{Determinação do coeficiente de atrito}

O ensaio é realizado a partir da movimentação de um bloco de ferro de 11,5 kg provido de um pedaço de couro para simular o uso de sapatos sobre a superfície da madeira. O bloco é sustentado por um cabo de aço ligado à célula de carga da maquina universal de ensaios. O conjunto é conectado ao computador para o registro das forças e adequação da velocidade de arraste do bloco (Figura 7).

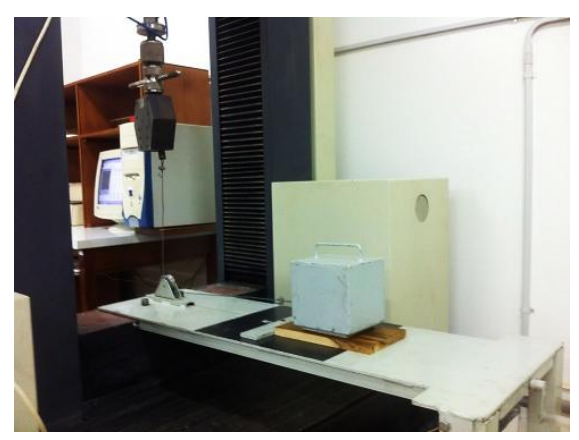


Figura 7: Adaptação da máquina universal para determinação do coeficiente de atrito

O coeficiente de atrito estático foi calculado a partir da equação 1 e o coeficiente de atrito dinâmico foi calculado pela equação 2 .

$$
\begin{array}{r}
\mu s=F s / P \\
\mu k=F k / P
\end{array}
$$

em que, Fs é a força máxima necessária para mover o artefato a uma velocidade de $1,27 \mathrm{~mm} / \mathrm{min}$, P é a massa do artefato, $F k$ é a força média necessária para manter o artefato a uma velocidade de $51 \mathrm{~mm} / \mathrm{min}$.

Para os ensaios de atrito se empregaram três tipos de tratamentos, quais sejam: a madeira sem acabamento, a madeira com três camadas de Stain e a madeira com cera incolor, todas previamente lixadas e polidas.

\subsection{Rugosidade da superfície}

As medições da rugosidade superficial foram realizadas com rugosímetro de arraste Surtronic 3+ (Taylor Hobson) e determinados os parâmetros de rugosidade superficial, $R a$ (média), $R t$ (máxima) e $R z$ (total). $\mathrm{O}$ comprimento de amostragem (cut-off) utilizado foi de $0,8 \mathrm{~mm}$ e o comprimento de medição foi de $8 \mathrm{~mm}$, conforme metodologia descrita por HIZIROGLU et al [17] e BRAGA et al [18] (Figura 8)

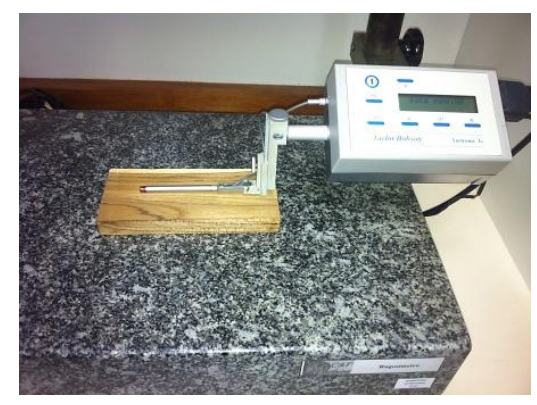

Figura 8: Medição da rugosidade da superfície da madeira

\subsection{Análises estatísticas}

Para os ensaios de carga rolante, endentação e abrasão foi utilizada estatística descritiva com o número de repetições indicados na tabela 2 . No ensaio de impacto de esfera de aço foi utilizada a análise de regressão linear, sendo testado o modelo exponencial. $\mathrm{O}$ teste de Bartlett a $5 \%$ de probabilidade se usou para determinar a homogeneidade da variância. Já para avaliação dos efeitos qualitativos do tipo acabamento no coeficiente de atrito e na rugosidade da superfície se empregou o delineamento experimental inteiramente casualizado de três 3 tratamentos e 10 repetições. Para avaliação foram utilizados testes de comparação múltipla das medias com teste (Scott-Knott a 5\% de significância).

\section{RESULTADOS E DISCUSSÃO}

\subsection{Ensaio de carga rolante}

Os valores médios da depressão produzidos em cada ciclo (10, 25 e 50), corresponderam a 0,30, 0,37, e 0,44 milímetros respectivamente, os quais são mostrados na Figura 9. 


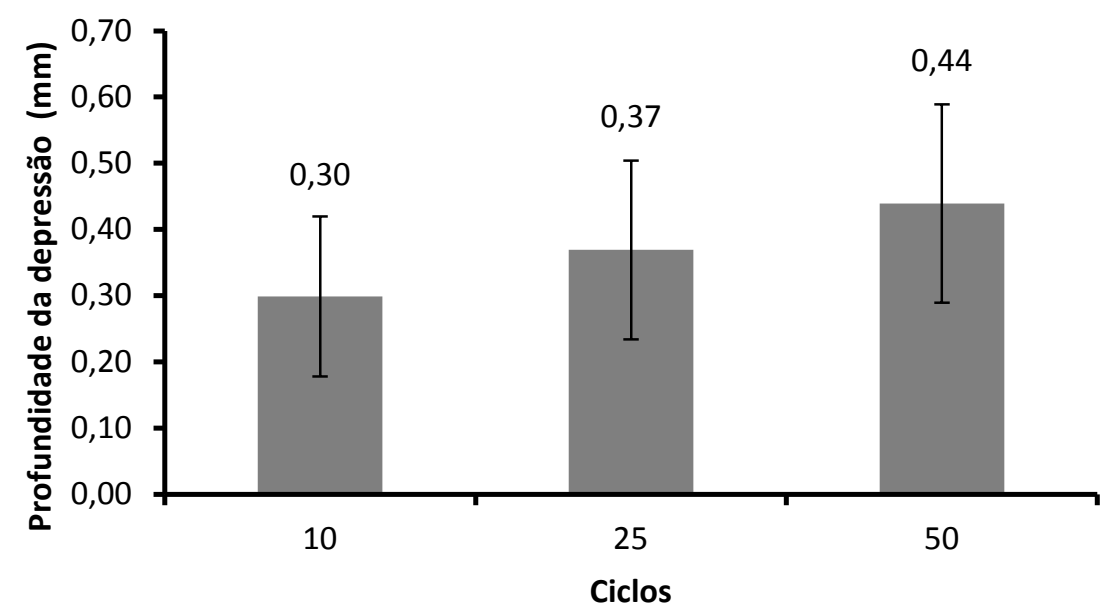

Figura 9: Profundidade média da depressão por número de ciclos em carga rolante

Este esforço aplicado no piso simula o efeito de cargas dinâmicas periódicas no sentido normal às fibras da madeira que variam em função do tempo. As fibras que compõem a madeira são achatadas, portanto, sob o esforço nesta direção sofrem deformação e esmagamento com o aumento da carga que avançam gradualmente desde a superficie para o interior da madeira, o que resulta em desgaste da superficie devido a redução do tamanho das cavidades celulares [19]. Isto explica que com o aumento do número de passagens da carga sobre a madeira a depressão aumenta gradativamente, como mostrado na Figura 9. Na madeira, a densidade é um reflexo da quantidade de parede celular presente por unidade de área, e esta por sua vez é uma função do tipo e tamanho das células. [20]. Como a densidade varia dependendo da espécie, isto explica a diferencia entre a resposta das diferentes madeiras, desta forma a densidade é a principal propriedade a considerar para as diversas utilizações na industria.

Estudos envolvendo ensaios de simulação em serviço de pisos reportados em outras espécies indicam que o aumento da densidade da madeira resulta em redução das depressões obtidas, por exemplo, os valores obtidos tomando como referencia a viagem No.50 em ensaio de pisos em madeiras de Eucalyptus, cuja densidade variou de 0,74 a $0,80 \mathrm{~g} / \mathrm{cm}^{3}$ foram de 0,206 a $0,265 \mathrm{~mm}$.[15]. SANTOS et al [13], avaliando pisos de Eucalyptus com dez anos de idade determinaram depressões para ensaio de carga rolante de 0,358 a 0,365 $\mathrm{mm}$, sendo que a densidade variou de 0,576 a $0,615 \mathrm{~g} / \mathrm{cm}^{3}$. Estes valores, portanto, foram superiores aos relatados neste estúdio, sendo a densidade da teca $0,54 \mathrm{~g} / \mathrm{cm}^{3}$ [8]. CORTEZ-BARBOSA et al[16] estudando o comportamento em serviço de pisos Edge Glued Painel da gramínea bambu e Pinus, encontraram uma depressão média para a viagem número 50 de $0,581 \mathrm{~mm}$. Por se tratar de madeira jovem, a teca estudada comparada com o bambu apresentou melhor performance, já que este último alcançou a depressão média na viagem No 25 similar a encontrada na teca na viagem No 50.

\subsection{Endentação por cargas aplicadas em pequenas áreas}

Na Tabela 3 encontram-se os valores médios para as endentações causadas pela passagem do rolo sobre a madeira para 100 viagens (uma passagem) na madeira de teca.

Tabela 3: Endentação produzida pelo ensaio de cargas aplicadas em pequenas áreas

\begin{tabular}{c|c}
\hline ESTATÍSTICAS & ENDENTAÇÃO (mm) \\
\hline $\mathrm{n}$ & 81 \\
\hline Média & 0,10 \\
\hline Máximo & 0,30 \\
\hline Mínimo & 0,0006 \\
\hline Desvio padrão & 0,06 \\
\hline
\end{tabular}

Os danos gerados a superfícies de pisos de madeira por efeito de saltos de sapatos altos é amplamente reportado pelos usuários. A superfície apresenta falhas na forma de depressões devido ao esmagamento das 
fibras em pontos localizados, estas falhas ou áreas de ruptura na madeira devem-se a regiões microscópicas em que a tensão localizada torna-se muito maior que a tensão media que atua sobre toda a seção. Da mesma forma que na resistência a carga rolante, a resistência à endentação depende da densidade e dureza do material, esta última relaciona a resistência da madeira a penetração de corpos estranhos. [19]. A média das depressões observadas na madeira de teca foi também superior às encontradas na literatura, o valor médio de 0,10 mm foi superior ao registrado por MARTINS et al [15], com depressão média de 0,023 mm em Eucalyptus cloeziana. PADILHA et al [11] em clones de Eucalyptus urophylla determinaram depressões de 0,05 mm e SANTOS et al [13], de 0,06 mm também em Eucalyptus. Os resultados foram similares aos determinados por CORTEZ-BARBOSA et al [16] em ensaios de pisos EGP de bambu e Pinus com médias de endentação de 0,08 mm. De forma qualitativa segundo a norma ASTM - D 2394-05 [10] pode-se classificar como dano moderado (Figura 10). GONZALEZ [12] também determinou baixa resistência e dano severo a este tipo de esforço em ensaios com a espécie Gmelina arborea também da família botânica da teca.

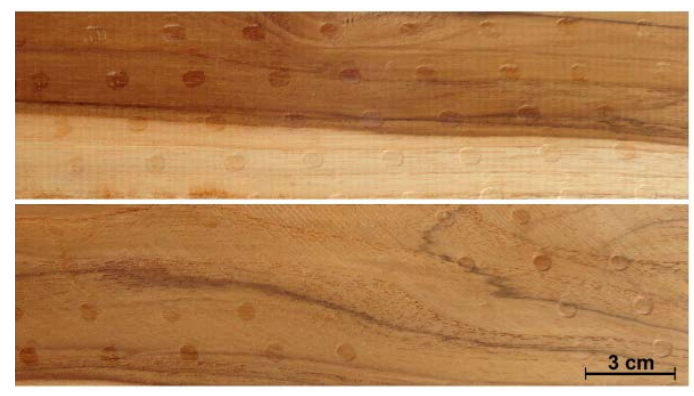

Figura 10: Dano moderado na superfície da madeira de teca após o ensaio de endentação em pequenas áreas

\subsection{Ensaio da esfera de aço}

A madeira apesar de possuir comportamento elástico até certo ponto, por ser um material com comportamento moderadamente dúctil, absorbe a energia ocasionada pelo impacto na forma de deformação antes da ruptura. Ocorre impacto quando um objeto atinge outro e assim forças intensas desenvolvem-se entre eles durante um curto período de tempo [21]. Quando a esfera de aço é liberada da inercia sobre a superfície da madeira, esta absorbe a energia de impacto na forma de deformação, a qual é incrementada com o aumento da distância em que a esfera é liberada. A Figura 11 mostra a relação da depressão causada pelo impacto da queda da esfera de aço em função da altura. Quanto maior a altura de queda da esfera, maior a depressão causada na madeira com tendência exponencial de incremento. A altura máxima de queda correspondente a $180 \mathrm{~cm}$ é usada como padrão de comparação, cuja média de 0,50 mm foi superior aos estudos reportados por outros autores. Em estudos de impacto de esfera de aço em Eucalyptus urophylla PADILHA et al [11]determinaram valores máximos de depressão de 0,468 mm, SANTOS et al [13] também em de Eucalyptus, com 0,348 mm em média. MARTINS et al [15] de 0,265. Já CORTEZ-BARBOSA et al [16] em pisos EGP de bambu e Pinus, determinaram a depressão de 0,366 mm. A resposta em termos de resistência ao impacto apresentou-se baixa, portanto é necessário proteger a madeira para eventuais quedas de objetos sobre o piso para evitar deformações e danos. 


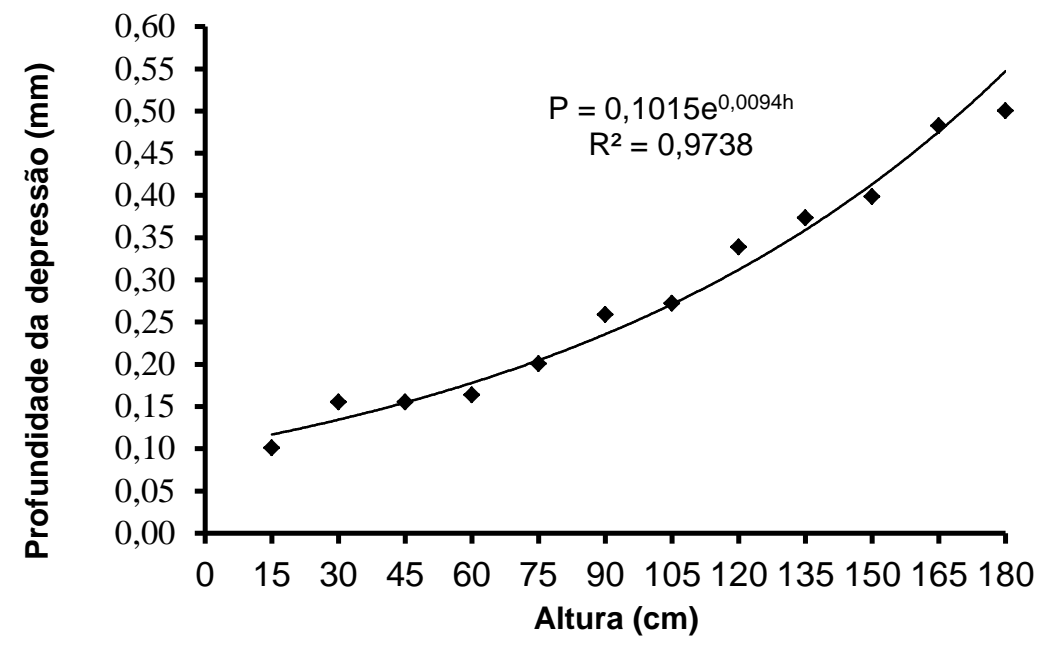

Figura 11: Profundidade da depressão em função da altura no ensaio de impacto de esfera de aço

\subsection{Ensaio de abrasão}

A resistência à abrasão é um dos aspectos mais importantes para determinar o desempenho da vida em serviço de pisos de madeira. A superfície está sujeita à remoção de partículas por elementos abrasivos, trânsito de pessoas, deslocamentos de objetos, entre outros, diminuindo assim a vida útil do piso. O desgaste é medido como a redução da espessura resultante da abrasão. Na tabela 4 encontram-se os dados médios da depressão obtida após 500 ciclos de abrasão. Estudos relacionados com desgaste de superfícies de pisos de relataram valores baixos de desgaste, por exemplo, MARTINS et al [15] em Eucalyptus cloeziana com média de 0,055 mm de depressão, no entanto, CORTEZ-BARBOSA et al [16], em ensaios de abrasão em pisos EGP de bambu e Pinus, obtiveram valores de 0,08 mm para 500 ciclos, valor aproximado ao determinado neste estudo. Ensaios de abrasão para Bambu (Phyllostachys pubescens) também foram realizados por BERNDSEN et al [22], o estudo determinou que maiores densidades nem sempre apresentam uma maior resistência ao desgaste. No presente estudo, considerando a densidade básica da madeira de teca $\left(540 \mathrm{~kg} / \mathrm{m}^{3}\right)$, pode-se dizer que essa madeira apresentou uma resistência alta ao desgaste, comparando com outras espécies com maior densidade.

Tabela 4: Depressão na madeira de teca devido ao ensaio de abrasão

\begin{tabular}{c|c}
\hline ESTATÍSTICAS & DEPRESSÃO (mm) \\
\hline $\mathrm{n}$ & 43 \\
\hline Média & 0,10 \\
\hline Máximo & 0,24 \\
\hline Mínimo & 0,04 \\
\hline Desvio padrão & 0,04 \\
\hline
\end{tabular}

\subsection{Coeficiente de atrito}

O ensaio de atrito ou fricção determina o valor da resistência de um material sobre outro, ou define-se como a força necessária para manter o movimento relativo de dois corpos. Nos pisos de madeira o coeficiente de atrito representa a resistência ao escorregamento e é um fator de segurança influenciado por vários fatores como o acabamento e qualidade da superfície. O coeficiente de atrito estático representa a força máxima necessária que se opõe ao início do movimento e o coeficiente de atrito dinâmico, a força necessária que se opõe a continuação do movimento relativo [23].

Na Tabela 5 encontram-se os valores médios dos coeficientes de atrito dinâmico e estático da madeira de teca, além do teste de comparação múltipla realizado. Pode-se observar que o tratamento de acabamento 
com cera incolor influenciou significativamente o atrito estático, devido à superfície mais lisa. Entretanto, para o coeficiente de atrito dinâmico o tratamento sem acabamento apresentou o menor valor, indicando menor força necessária para a continuação do movimento, portanto, garante mais segurança ao escorregamento, contudo o acabamento oferece maior qualidade estética e proteção. O tratamento de cera incolor proporcionou o menor valor de coeficiente de atrito estático e um coeficiente de atrito dinâmico intermediário.

Tabela 5: Comparação múltipla das médias para os valores médios dos coeficientes de atrito

\begin{tabular}{c|c|c}
\hline \multirow{2}{*}{ TRATAMENTO } & \multicolumn{2}{|c}{ COEFICIENTE DE ATRITO } \\
\cline { 2 - 3 } & Estático & Dinâmico \\
\hline Sem acabamento & $0,37 \mathrm{a}$ & $0,18 \mathrm{a}$ \\
\hline Stain & $0,45 \mathrm{a}$ & $0,30 \mathrm{~b}$ \\
\hline Cera incolor & $0,26 \mathrm{~b}$ & $0,25 \mathrm{~b}$ \\
\hline
\end{tabular}

Médias seguidas de, pelo menos, uma mesma letra na vertical não diferem entre si a 5\% de significância, pelo teste de Scott-Knott.

MARTINS et al [15] determinaram coeficientes de atrito para Eucalyptus de 0,25 e 0,15 para coeficiente estático e dinâmico, respectivamente. PADILHA et al [11] em Eucalyptus urophylla, encontraram valores de 0,37 e 0,23 para coeficiente estático e dinâmico, respectivamente. CORTES-BARBOSA et al [16] em pisos EGP de bambu e Pinus determinaram coeficiente de atrito estático de 0,31 e 0,24 para o dinâmico. Segundo BLAU [23] coeficientes de atrito para madeiras encontram-se entre 0,25 e 0,50 para atrito estático e 0,19 em média para atrito dinâmico, os quais são adequados para padrões de comparação. Os valores encontrados neste estudo indicam que a madeira de teca se encontra dentro dos parâmetros adequados para utilização em pisos no que diz a resistência ao escorregamento, principalmente da superfície sem acabamento, por exemplo, para utilização em decks, assoalhos, etc.

\subsection{Rugosidade da superfície}

Na Tabela 6 encontram-se os valores médios e o teste de comparação múltipla realizado para os parâmetros de rugosidade na madeira de teca. Observou-se diferença estatística significativa para a rugosidade média $(R a)$ e a rugosidade total $(R z)$. Observa-se que a rugosidade média $(R a)$ da superfície de madeira com os produtos de acabamento apresentou valores menores, o qual indica a superfície menos rugosa. Este fato acontece devido a que os produtos de acabamento preenchem os locais de fratura (elementos celulares da madeira), diminuindo as saliências e reentrâncias microscópicas no material, tornando-a mais lisa. Para a rugosidade máxima $(R z)$ que indica a média de 5 valores da rugosidade total no comprimento de avaliação, a madeira com produtos de acabamento também apresentou diferencia estatística refletida em valores menores de profundidade de picos e vales. As Figuras 7, 8 e 9 mostram os perfis da rugosidade para os tratamentos avaliados, indicando a profundidade dos picos e vales na superfície da madeira. A qualidade da superfície da madeira depende tanto do processamento, mas também da estrutura anatômica específica, uma vez que a madeira contém cavidades celulares que são independentes de qualquer processo de usinagem [24].

Tabela 6: Comparação múltipla das médias para os parâmetros de rugosidade

\begin{tabular}{c|c|c|c}
\hline TRATAMENTO & \multicolumn{3}{|c}{ PARÂMETROS DE RUGOSIDADE } \\
\hline & $R a$ & $R t$ & $R z$ \\
\hline $\begin{array}{c}\text { Sem produto de } \\
\text { acabamento }\end{array}$ & $2,36 \mathrm{a}$ & $22,90 \mathrm{a}$ & $13,18 \mathrm{a}$ \\
\hline Stain & $0,98 \mathrm{~b}$ & $14,34 \mathrm{a}$ & $5,64 \mathrm{~b}$ \\
\hline Cera incolor & $1,24 \mathrm{~b}$ & $15,13 \mathrm{a}$ & $6,70 \mathrm{~b}$ \\
\hline
\end{tabular}




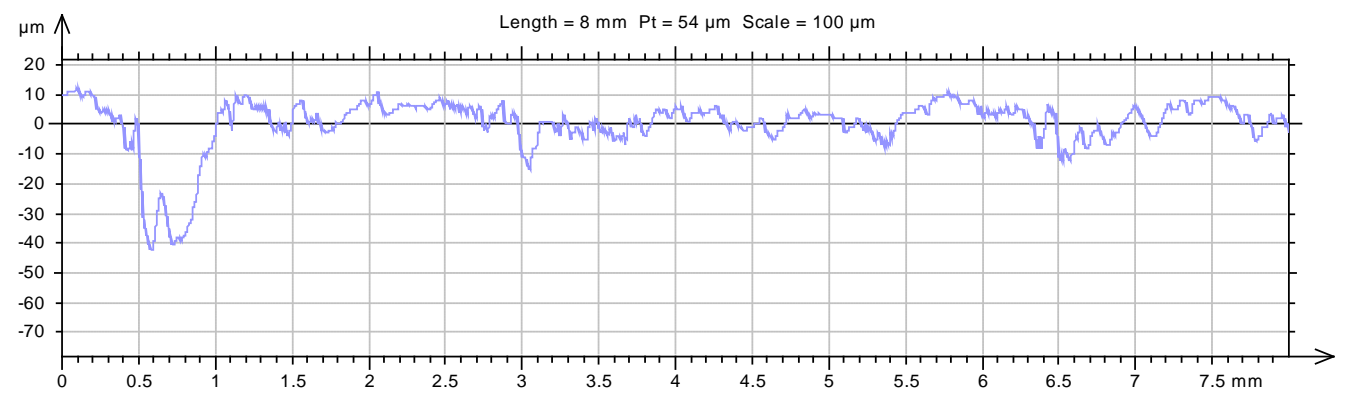

Figura 7: Perfil de rugosidade para a madeira de teca para pisos sem produto de acabamento, $R a=2,75$

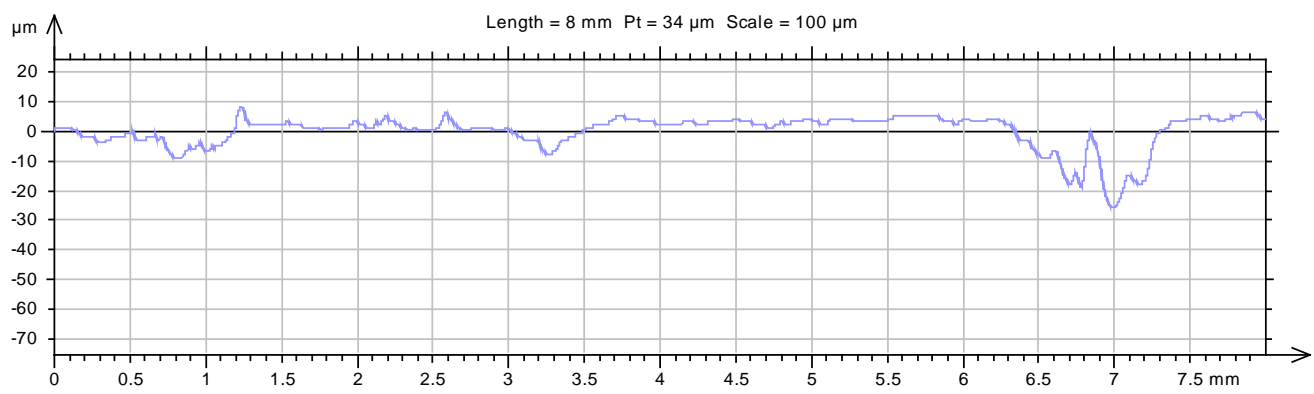

Figura 8: Perfil de rugosidade para a madeira de teca para pisos com stain, $R a=0,94$

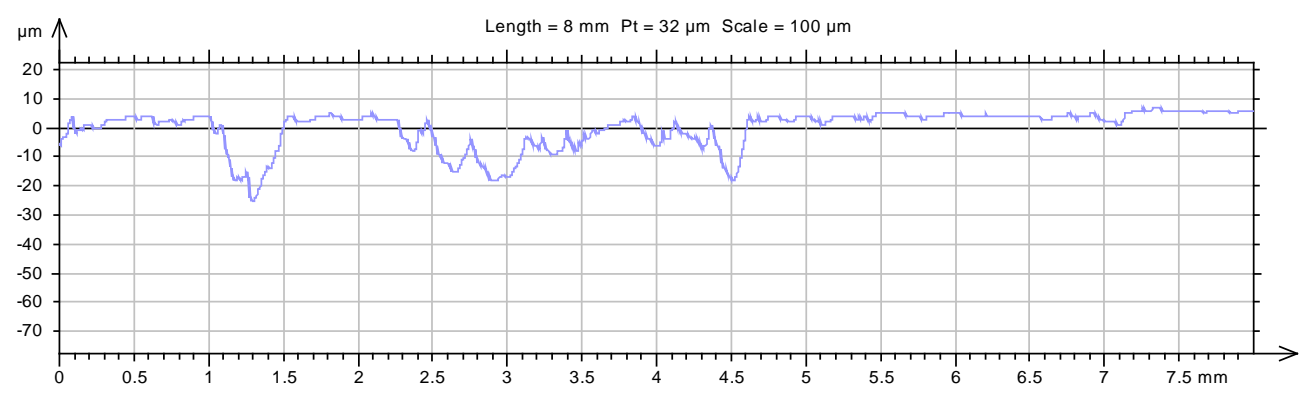

Figura 9: Perfil de rugosidade para a madeira de teca para pisos com cera incolor, $R a=1,92$

\section{CONCLUSÕES}

Os resultados permitem concluir que:

- $\quad$ A madeira de teca apresentou resistência moderada a esforços de carga rolante.

- Para o ensaio de endentação em pequenas áreas a madeira não teve resposta satisfatória, apresentando dano severo.

- $\quad$ O ensaio de impacto da esfera de aço mostrou baixa resistência à queda de objetos sobre o piso.

- A resistência à abrasão foi satisfatória em termos de desgaste comparada com espécies de maior densidade básica.

- $\quad$ O acabamento na madeira influenciou no coeficiente de atrito, quanto mais lisa a superfície da madeira o coeficiente de atrito diminui oferecendo menor resistência ao escorregamento.

- $\quad$ A rugosidade da superfície é diminuída com a aplicação de produtos de acabamento.

- A madeira de teca em relação a sua densidade apresentou melhor desempenho em serviço comparada com espécies de Eucalyptus relatados na literatura, cujas densidades são superiores.

- Recomenda-se o uso desta madeira em tráfego leve como residências e pequenos escritórios, onde a madeira não se submeta a aplicação de grandes esforços. 


\section{AGRADECIMENTOS}

Os autores agradecem as agencias de Fomento CAPES, CNPQ e FAPEMIG pelo auxilio financeiro da pesquisa, também ao Programa Estudante-Convênio de Pós-graduação (PEC-PG) da CAPES-Ministério das Relações Exteriores, pelo apoio financeiro da primeira autora.

\section{BIBLIOGRAFIA}

[1] http://www.freedoniagroup.com/Hard-Surface-Flooring.html. Acesso em: 6 de julho de 2015.

[2] ASSOCIAÇÃO NACIONAL DOS PRODUTORES DE PISOS DE MADEIRA. ANPM, http://www.anpm.org.br/?S=48\&L=1. Acesso em: 1 de abril de 2015.

[3] ASSOCIAÇÃO BRASILEIRA DE PRODUTORES DE FLORESTAS PLANTADAS. ABRAF. Anuário estatístico da ABRAF 2013, ano base 2012. Brasília, 2013. Disponível em: <http://www.abraflor.org.br/estatisticas.asp>. Acesso em: 1 abril de 2015.

[4] BHAT, K.M. "Properties of fast-grown teakwood: impact on end-users requirements”, Journal of Tropical Forest Science, v.4, n.1, pp.1-10, 1998.

[5] FAO (Food and Agriculture Organization of the United Nations). 2009b. Situación de los bosques en el mundo. Roma. Disponible en: http://www.fao.org. Fecha de acceso: 15/11/2010.

[6] MOYA, R., BOND, B., QUESADA, H. “A review of heartwood properties of Tectona grandis trees from fast-growth plantations”, Wood Science and Technology, n. 48, pp.411-433, 2014

[7] BHAT, K.M., PRIYA, P.B., RUGMINI, P. “Characterisation of juvenile wood in teak”, Wood Science and Technology, v.34. n.6, pp.517-532, 2001.

[8] BLANCO-FLÓREZ, J., FERNANDO-TRUGILHO, P., TARCISIO-LIMA, J., et al. “Caracterización de la madera joven de Tectona grandis L. f. plantada en Brasil”, Madera y Bosques, v.20, n.1, pp.11-20. 2014.

[9] UNITED STATES FOREST PRODUCTS LABORATORY. Simulated service testing of wood and wood-base finish flooring, Wisconsin, 1971.

[10] AMERICAN SOCIETY FOR TESTING AND MATERIALS.ASTM - D 2394-05. "Simulated service testing of wood and wood-base finish flooring”, Annual book of ASTM standards, 2011.

[11] PADILHA, C., LIMA, J. T., SILVA, J. R. M. “Avaliação da qualidade da madeira de Eucalyptus urophylla para utilização em pisos”, Scientia Florestalis, n.7, pp. 141-147, 2006.

[12] GONZALEZ, G. "Pisos de madera”, Kurú Revista Forestal, v.3, n.7, pp. 1-9, 2006.

[13] SANTOS, I. S., LIMA, J,T., SILVA, J.R.M. “Avaliação dos pisos produzidos a partir de toras de clones de Eucalyptus sp. com pequenos diâmetros”, Cerne, v.16, n.4, pp. 473-478, out./dez. 2010.

[14] KNAPIC, S., MACHADO, J. S., PEREIRA, H. "Properties of cork oak wood related to solid wood flooring performance”, Construction and Building Materials, v.30, pp.569-573, 2012.

[15] MARTINS, et al., "Simulação em uso de pisos de madeira de Eucalyptus sp e Corymbia maculata”, Cerne, v.19, n.1, pp. 151-156. 2013.

[16] CORTEZ-BARBOSA, J., SILVA, J.R.M, ALVARENGA, F., et al. "Simulation Analysis of In-Service Bamboo and Pine EGP Composite Flooring”, Advanced Materials Research., v.1025-1026, pp.233-240, 2014.

[17] HIZIROGLU, S., ANWAR, U.M.K., HAMDAN, H., et al, "Evaluation of surface quality of some Malaysian species as function of outdoor exposure”, Journal of Materials Processing Technology, v. 199, n. 1-3, pp. 156-162, 2008.

[18] BRAGA,P.P.C, SILVA, J.R.M, NÉRI, A.C., et al, “Qualidade da superfície de madeira de Coffea arábica C Cerne”, Cerne, v. 20, n. 1, Jan./Mar. 2014.

[19] TSOUMIS,G., Science and Technology of Wood , Nova Iorque, Van Nostrand Reinhold, 1991.

[20] BARNETT, J, JERONIMIDIS G., Wood Quality and its Biological Basis, EUA, Wiley-Blackwell, 2009.

[21] HIBBELER R.C, Resistencia dos Materiais, 7 ed., EUA, Pearson Prentice hall, 2010.

[22] BERNDSEN, R.S, KLITZKE, R.J, BATISTA, D.C., et al, "Mechanical resistance of moso bamboo (Phyllostachys pubescens) part 2: axial tensile strength, hardness and wear resistance”, Floresta, v. 44, n. 3, pp. 505 - 514, jul. / set. 2014. 
BLANCO-FLÓREZ, J.; SILVA, J. R. M.; BRAGA, P. P. C.; LIMA, J. T.; TRUGILHO, P.F. revista Matéria, v.20, n.4, pp. 1048 - 1060,

[23] BLAU, P, J, “The significance and use of the friction coefficient”, Tribology International, v.34 pp.585-591, 2001

[24] GURAU, L., MANSFIELD-WILLIAMS, H , IRLE, M., "Processing roughness of sanded wood surfaces”, Holz Roh Werkst, n. 63, pp.43-52, 2005.

[25] MAGOSS, E., “General Regularities of Wood Surface Roughness”, Acta Silv. Lign. Hung, v.4, pp.8193. 2008. 